\title{
Meta-analysis of Placebo-Controlled Randomized Controlled Trials on the Prevalence of Statin Intolerance
}

\author{
Haris Riaz, MD ${ }^{\mathrm{a}} *$, Abdur Rahman Khan, MD ${ }^{\mathrm{b}}$, Muhammad Shahzeb Khan, MD $^{\mathrm{c}}$, \\ Karim Abdur Rehman, MDa, Shehab Ahmad Redha Alansari, MD, Bashaer Gheyath, MD \\ Sajjad Raza, MD ${ }^{\mathrm{d}}$, Amr Barakat, MD ${ }^{\mathrm{a}}$, Faraz Khan Luni, MD ${ }^{\mathrm{e}}$, Haitham Ahmed, MD, MPH ${ }^{\mathrm{f}}$, and \\ Richard A. Krasuski, MD
}

\begin{abstract}
The prevalence of intolerance varies widely. Stopping statin therapy is associated with worse outcomes in patients with cardiovascular disease. Despite extensive studies, the benefits and risks of statins continue to be debated by clinicians and the lay public. We searched the PubMed, Medline, and Cochrane Central Register of Controlled Trials (CENTRAL) databases for all randomized controlled trials of statins compared with placebo. Studies were included if they had $\geq 1,000$ participants, had patients who were followed up for $\geq 1$ year, and reported rates of drug discontinuation. Studies were pooled as per the random effects model. A total of 22 studies (statins $=66,024$, placebo $=63,656$ ) met the inclusion criteria. The pooled analysis showed that, over a mean follow-up of 4.1 years, the rates of discontinuation were $13.3 \%(8,872$ patients) for statin-treated patients and $13.9 \%(8,898$ patients) for placebo-treated patients. The random effects model showed no significant difference between the placebo and statin arms (odds ratio $[\mathrm{OR}]=0.99,95 \%$ confidence interval $[\mathrm{CI}]=0.93$ to 1.06 ). The results were similar for both primary prevention $(\mathrm{OR}=0.98,95 \% \mathrm{CI}=0.92$ to $1.05, \mathrm{p}=0.39)$ and secondary prevention $(\mathrm{OR}=0.92,95 \% \mathrm{CI}=0.83$ to $1.05, \mathrm{p}=0.43)$ studies. The pooled analysis suggested that the rates of myopathy were also similar between the statins and placebos $(\mathrm{OR}=1.2,95 \% \mathrm{CI}=0.88$ to $1.62, p=0.25$ ). In conclusion, this meta-analysis of $>125,000$ patients suggests that the rate of drug discontinuation and myopathy does not significantly differ between statin- and placebo-treated patients in randomized controlled trials. These findings are limited by the heterogeneity of results, the variable duration of follow-up, and the lower doses of statins compared with contemporary clinical practice. ㅇ 2017 Elsevier Inc. All rights reserved. (Am J Cardiol 2017;120:774-781)
\end{abstract}

Statin intolerance is a common phenomenon and is reported in $5 \%$ to $20 \%$ of patients, often resulting in drug discontinuation. ${ }^{1}$ Stopping statin therapy has been associated with worsened outcomes in patients with cardiovascular diseases (CVDs). ${ }^{2}$ With acceptance of the latest American College of Cardiology guidelines, the number of patients who require treatment with statins has increased even further. ${ }^{3} \mathrm{~A}$ number of mechanisms have been proposed to explain the phenomenon of statin intolerance. However, despite extensive studies, statin intolerance remains an elusive phenomenon.

${ }^{\mathrm{a}}$ Heart and Vascular Institute, Cleveland Clinic, Cleveland, Ohio; 'bepartment of Cardiovascular Medicine, University of Louisville, Louisville, Kentucky; ${ }^{\circ}$ Department of Internal Medicine, John H Stroger Jr. Hospital of Cook County, Chicago, Illinois; ' ${ }^{D}$ epartment of Cardiac Surgery, Heart and Vascular Institute, Cleveland Clinic, Cleveland, Ohio; ${ }^{\mathrm{e} D e p a r t m e n t}$ of Cardiovascular Medicine, Mercy Saint Vincent Medical Center, Toledo, Ohio; fSection of Preventive Cardiology, Heart and Vascular Institute, Cleveland Clinic, Cleveland, Ohio; and ${ }^{\mathrm{g}}$ Department of Cardiovascular Medicine, Duke University Medical Center, Durham, North Carolina. Manuscript received February 22, 2017; revised manuscript received and accepted May 30, 2017.

See page 780 for disclosure information.

*Corresponding author: Tel: +1 216644 7103; fax: 216-644-7103.

E-mail address: riazh@ccf.org (H. Riaz).
Most of our knowledge of the incidence of statin intolerance stems from observational studies and post hoc analyses. Assessing statin intolerance is important, as it can have widespread implications on public health. A number of patients on statins report muscle-related symptoms. There is little consensus among clinicians on whether to attribute muscle symptoms to statins; and in the absence of confirming laboratory parameters, judgment frequently remains subjective. Given this backdrop, we conducted a rigorous meta-analysis of historical randomized controlled trials (RCTs) to compare the rates of drug discontinuation for patients treated with statins and for patients treated with placebo.

\section{Methods}

A PubMed and Medline literature search was conducted using the keywords "statin" and "clinical trials" (phase 1, phase 2, phase 3 , and phase 4 ) as a filter. We also searched for "metaanalysis" as the article type and hand searched the reference lists of the selected systematic reviews to identify further studies. We also searched the Cochrane Central Register of Controlled Trials (CENTRAL) database to expand the literature search using the keywords "statin AND placebo." No language restrictions were applied and the databases were searched from the inception of these databases until October 2016. 
We only included clinical trials that enrolled at least 1,000 patients, had a placebo comparator arm, and had a followup of at least 1-year duration. This was done to ensure that only large clinical trials with a robust follow-up were included. We did not distinguish between the type of statin or the dose, albeit subgroup analyses were performed to examine whether these factors impacted outcomes. Similarly, we included studies whether they were done for primary or for secondary prevention of a related atherosclerotic condition such as ischemic stroke. Although we did not use surgical studies as screening criteria, many of these studies were small and were therefore excluded.

The bibliographies of the included trials were also searched to identify any missing studies. Similarly, we searched the systematic reviews of statins over the last 10 years and individually reviewed their reference lists to identify any missing data. Statin intolerance was defined by the rates of discontinuation without categorization of the specific adverse effect of statins. Therefore, we included only clinical trials where the discontinuation rates in the statin and placebo arms were reported without con- sideration of the major adverse cardiovascular end points, as the efficacy data of statins were already well established.

Given the significant heterogeneity of the included studies, we constructed a random effects model to pool the results using the using STATA 10 (StataCorp, College Station, TX). We assessed heterogeneity with the $\mathrm{I}^{2}$ statistic. Subgroup analyses were performed to assess the impact of the individual statins or for using statins for primary or secondary prevention. The Cochrane collaboration's tool was used for the ascertainment of bias. A funnel plot was made to assess for publication bias.

\section{Results}

The consort diagram (Figure 1) reviews the process used for study selection. A total of 22 studies (statins $=66,024$, placebo $=63,656$ ) fully met the inclusion criteria. ${ }^{4-25}$ The baseline demographics of the 129,680 included patients are listed in Table 1 . The pooled analysis showed that, over a mean follow-up of 4.1 years, the rates of discontinuation were $13.3 \%$

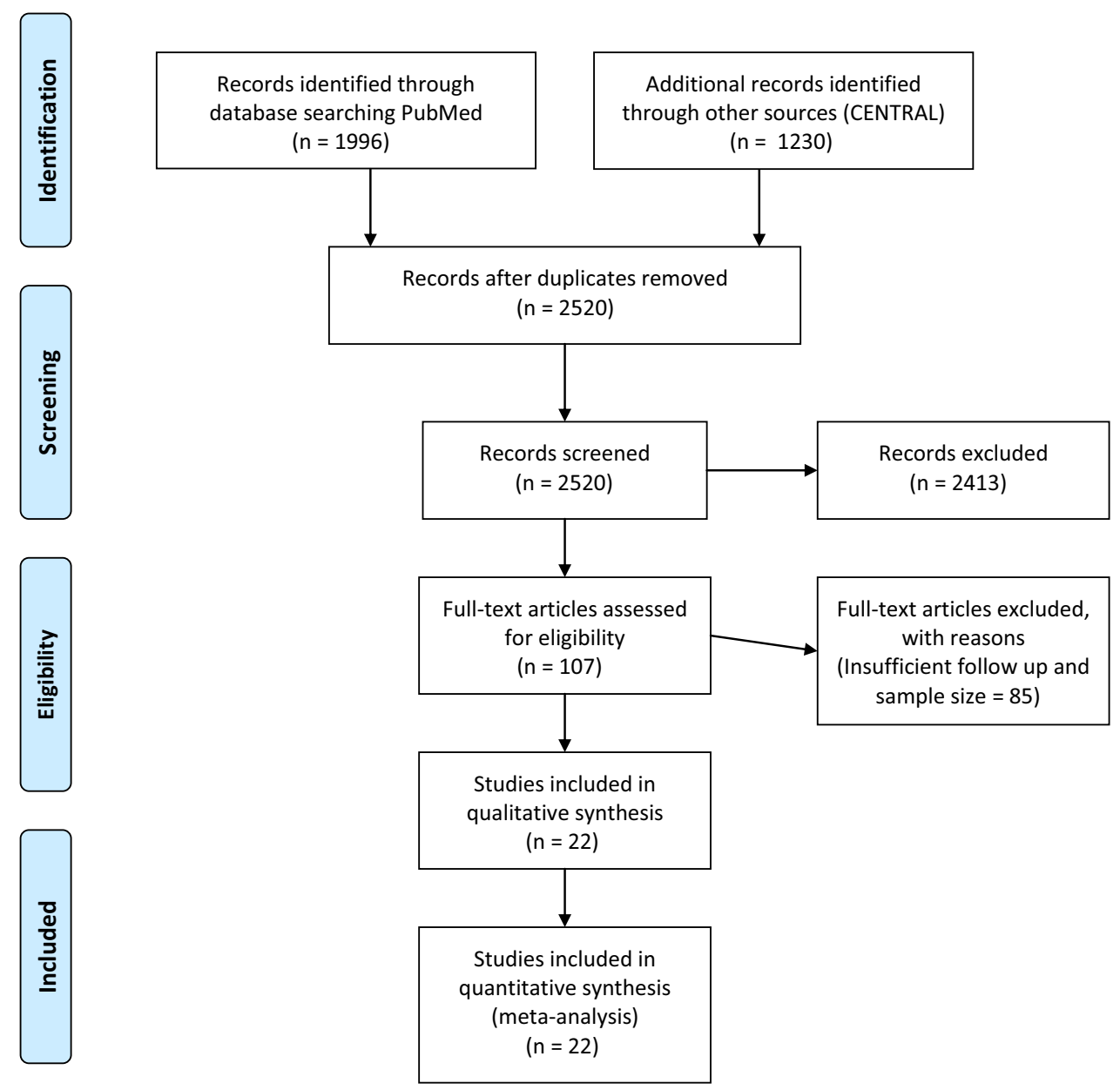

From: Moher D, Liberati A, Tetzlaff J, Altman DG, The PRISMA Group (2009). Preferred Reporting /tems for Systematic Reviews and MetaAnalyses: The PRISMA Statement. PLoS Med 6(7): e1000097. doi:10.1371/journal.pmed1000097

For more information, visit www.prisma-statement.org.

Figure 1. Preferred Reporting Items for Systematic Reviews and Meta-Analysis flow diagram highlighting the search strategy. 
Table 1

Baseline characteristics of the included studies*

\begin{tabular}{|c|c|c|c|c|c|c|c|c|c|}
\hline Trial Name & Country & Sample Size & Type of Statin & Follow up(years) & Age(years) & Females & Hypertension & Diabetes & Cardiovascular Disease \\
\hline $4 d^{6}$ & Multi-Centre & $619 / 636$ & Atorvastatin & 4 & $66 / 66$ & $46 / 46(\%)$ & - & - & $28 / 31(\%)$ \\
\hline $\operatorname{SSSS}^{23}$ & Scandinavia & $2221 / 2223$ & Simvastatin & 5.4 & $58 / 58$ & $18 / 19(\%)$ & $26 / 26(\%)$ & $5 / 4(\%)$ & $9 / 7(\%)$ \\
\hline Sparcle $^{22}$ & Multi-Centre & $2365 / 2366$ & Atorvastatin & 4.9 & $63 / 63$ & $40 / 41(\%)$ & $62 / 61(\%)$ & $17 / 17(\%)$ & - \\
\hline $\operatorname{Mega}^{20}$ & Japan & $3866 / 3966$ & Pravastatin & 5.3 & $58 / 58$ & $68 / 69(\%)$ & $42 / 42(\%)$ & $21 / 21(\%)$ & $0 / 0$ \\
\hline Prosper $^{21}$ & Scotland, Ireland, Holland & $2891 / 2913$ & Pravastatin & 3.2 & $75 / 75$ & $52 / 52(\%)$ & $62 / 62(\%)$ & $10 / 11(\%)$ & $45 / 43(\%)$ \\
\hline LIPS $^{19}$ & Multi-Centre & $844 / 833$ & Fluvastatin & 3.9 & $60 / 60$ & $16 / 17(\%)$ & $39 / 38(\%)$ & $14 / 10(\%)$ & $44 / 44(\%)$ \\
\hline LIPID $^{18}$ & Multi-Centre & $4512 / 4502$ & Pravastatin & 6.1 & $62 / 62$ & $17 / 17(\%)$ & $41 / 42(\%)$ & $9 / 9(\%)$ & $27 / 27(\%)$ \\
\hline Jupiter $^{17}$ & Multi-Centre & $8901 / 8901$ & Rosuvastatin & 1.9 & $66 / 66$ & $39 / 38(\%)$ & - & - & - \\
\hline Heart $S^{16}$ & UK & $10269 / 10267$ & Simvastatin & 5 & - & - & - & - & - \\
\hline Gissi $_{H} F^{15}$ & Italy & $2285 / 2289$ & Rosuvastatin & 3.9 & $68 / 68$ & $24 / 21(\%)$ & $55 / 53(\%)$ & $27 / 25(\%)$ & $32 / 34(\%)$ \\
\hline CORONA $^{14}$ & Multi-Centre & $2514 / 2497$ & Rosuvastatin & 2.7 & $73 / 73$ & $24 / 24(\%)$ & $63 / 63(\%)$ & 29/30(\%) & 60/60(\%) \\
\hline Care $^{13}$ & US/Canada & $2081 / 2078$ & Pravastatin & 5 & $59 / 59$ & 14/14(\%) & $42 / 43(\%)$ & $14 / 15(\%)$ & 100/100(\%) \\
\hline Cards $^{12}$ & Multi-Centre & $1428 / 1410$ & Atorvastatin & 3.9 & $62 / 62$ & $32 / 32(\%)$ & - & - & $0 / 0$ \\
\hline Aurora $^{11}$ & Multi-Centre & $1389 / 1384$ & Rosuvastatin & 3.2 & $64 / 64$ & $39 / 37(\%)$ & - & $28 / 25(\%)$ & $39 / 40(\%)$ \\
\hline Aspen $^{10}$ & Multi-Centre & $1211 / 1199$ & Atorvastatin & 4 & 61/61 & $34 / 33(\%)$ & $55 / 55(\%)$ & 100/100(\%) & $17 / 16(\%)$ \\
\hline Alliance $^{9}$ & USA & $1217 / 1225$ & Atorvastatin & 4.2 & 61/61 & 18/18(\%) & - & 23/21(\%) & 100/100(\%) \\
\hline Alert $^{8}$ & Multi-Centre & $1050 / 1052$ & Fluvastatin & 5.1 & $49 / 50$ & $33 / 35(\%)$ & 76/74(\%) & $19 / 19(\%)$ & $7 / 7(\%)$ \\
\hline AFSCAP $^{7}$ & USA & $3301 / 3304$ & Lovastatin & 5.2 & $58 / 58$ & $15 / 15(\%)$ & $22 / 22(\%)$ & $3 / 2(\%)$ & $0 / 0(\%)$ \\
\hline WOSCOPS $^{24}$ & Scotland & $3302 / 3293$ & Pravastatin & 4.9 & $55 / 55$ & $0 / 0(\%)$ & $16 / 15(\%)$ & $1 / 1(\%)$ & $5 / 5(\%)$ \\
\hline HOPE3 $3^{25}$ & Multi-Centre & $6361 / 6344$ & Rosuvastatin & 5.6 & $66 / 66$ & $46 / 46(\%)$ & $38 / 38(\%)$ & $13 / 13(\%)$ & $0 / 0(\%)$ \\
\hline METEOR $^{26}$ & Multi-Centre & $700 / 281$ & Rosuvastatin & 2 & $57 / 57$ & $40 / 41(\%)$ & $20 / 21(\%)$ & $8 / 11(\%)$ & $0 / 0(\%)$ \\
\hline Bradford $^{27}$ & USA & $2697 / 693$ & Lovastatin & 1 & 58 & $100(\%)$ & $42(\%)$ & - & $16(\%)$ \\
\hline
\end{tabular}

* Statin/Placebo. 


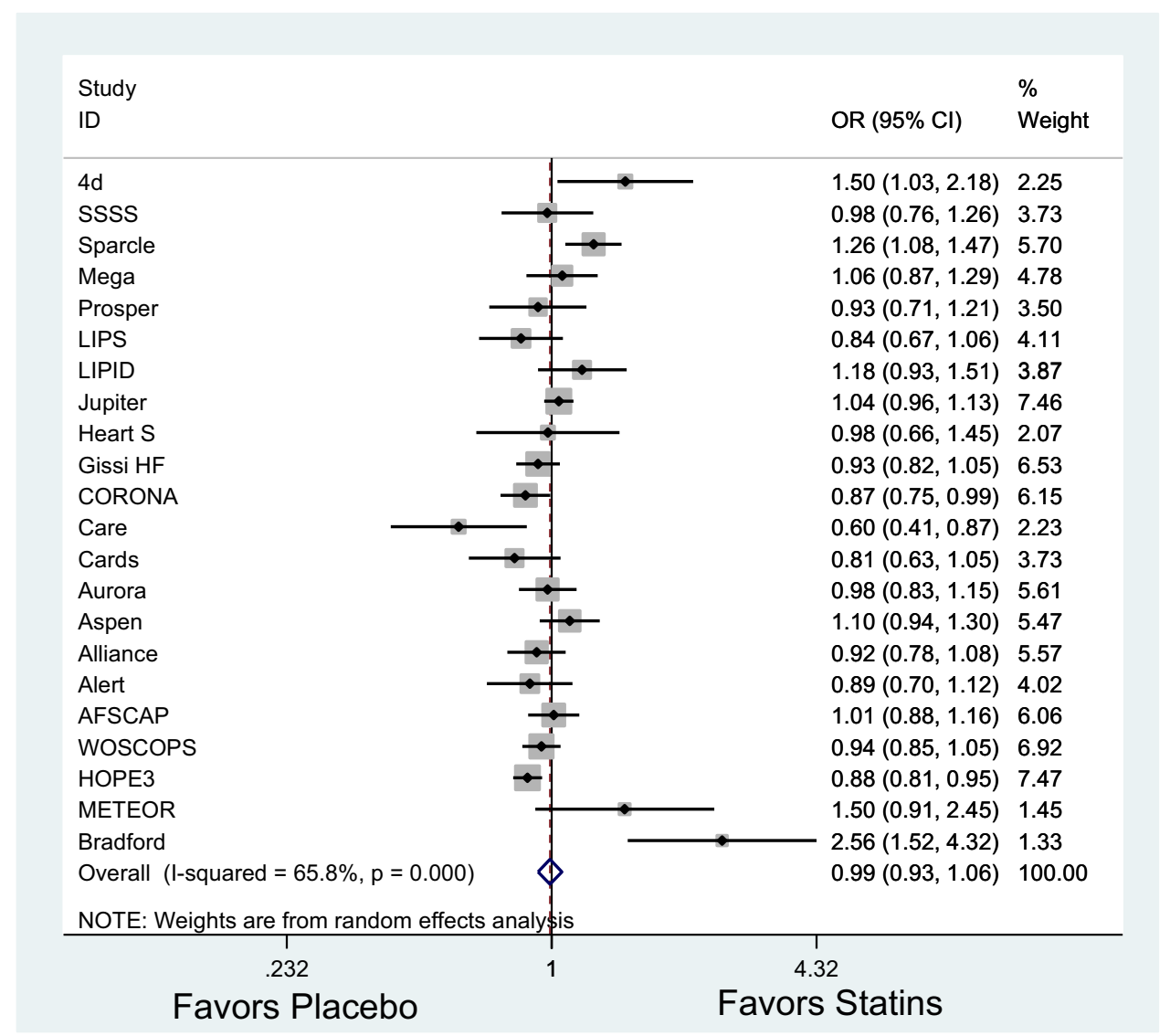

Figure 2. Discontinuation rates of statins versus placebos. AFSCAP $=$ The Air Force/Texas Coronary Atherosclerosis Prevention Study; CORONA $=$ Controlled Rosuvastatin Multinational Trial in Heart Failure; HF = heart failure; HOPE = Heart Outcomes Prevention Evaluation; LIPID = Long-term Intervention with Pravastatin in Ischaemic Disease; LIPS = Lescol Intervention Prevention Study; METEOR = Measuring Effects on Intima-Media Thickness: an Evaluation of Rosuvastatin; SSSS = Scandinavian Simvastatin Survival Study; WOSCOPS = The West of Scotland Coronary Prevention Study.

(8,872 patients) for statin-treated patients and $13.9 \%(8,898$ patients) for placebo-treated patients. The random effects model showed no significant difference between the placebo and statin arms (odds ratio $[\mathrm{OR}]=0.99,95 \%$ confidence interval $[\mathrm{CI}]=0.93$ to 1.06 ). Figure 2 represents the forest plot of all the included studies and pools the drug discontinuation between statin-treated and placebo-treated patients. Drug discontinuation rates were similar between groups for both primary $(\mathrm{OR}=0.98,95 \% \mathrm{CI}=0.92$ to $1.05, \mathrm{p}=0.39)$ and secondary $(\mathrm{OR}=0.92,95 \% \mathrm{CI}=0.83$ to $1.05, \mathrm{p}=0.42) \mathrm{CVD}$ prevention studies. We also pooled the data for myopathy as that is the most frequently cited reason for discontinuation. The pooled analysis suggested that the rates of myopathy were similar between the statin-treated and the placebo-treated patients $(\mathrm{OR}=1.2,95 \% \mathrm{CI}=0.88$ to $1.62, \mathrm{p}=0.25)$ (Figure 3$)$.

Several statin trials had a run-in phase where the patients were randomized to receive a statin or a placebo for a specified duration (e.g., 4 to 6 weeks). Only those patients who tolerated the placebo or the statin were subsequently included the trials. We reviewed the methodology (including that of the protocol) of all the RCTs and conducted a subgroup on the RCTs that did not have a run-in phase. This subgroup analysis of $14 \mathrm{RCTs}$ also showed that there was no difference in the rates of discontinuation between the statins and the placebos $(\mathrm{p}=0.97, \mathrm{OR}=0.99,95 \% \mathrm{CI}=0.9$ to 1.1 )
(Figure 4). Similarly, we conducted a subgroup analysis on the type of statin used and the rates of discontinuation. The subgroup analysis demonstrated no effect of the specific statin on the rates of discontinuation (Figure 5). The funnel diagram (Figure 6) demonstrated little evidence of publication bias in our study, with the studies being relatively well distributed.

\section{Discussion}

This meta-analysis of statin RCTs showed that the rates of discontinuation of statins are not significantly different from comparator placebos. Our conclusions are based upon the pooled analysis of many large RCTs that were robustly conducted with follow-up exceeding a year. These findings are reassuring, as statins have a consistent and reproducible track record of lowering major adverse cardiovascular events (including cardiovascular and all-cause mortality, major vascular events, and coronary revascularization) when used for either primary or secondary prevention. ${ }^{15}$ Although our subgroup analysis is limited by sample size, this phenomenon remains consistent regardless of which statin is utilized. We also conducted a subgroup analysis and excluded all the RCTs that had the run-in phase, thereby further decreasing the selection bias, and the findings still remained consistent.

The adverse effects of statins remain a contentious issue. The phrase "statin side effects" yields 670,000 hits on Google 


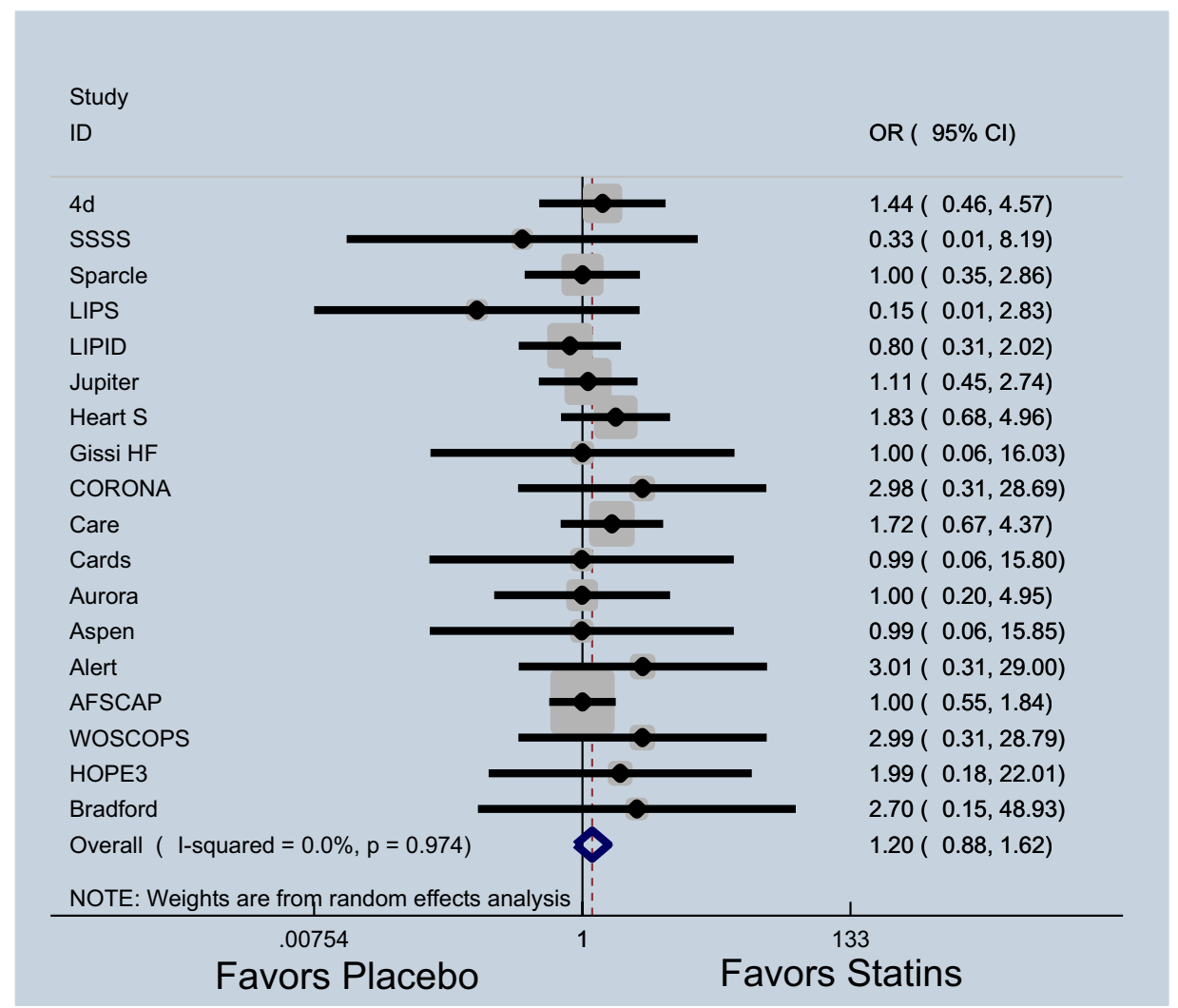

Figure 3. Rates of myopathy of statins versus placebos. AFSCAP = The Air Force/Texas Coronary Atherosclerosis Prevention Study; CORONA = Controlled Rosuvastatin Multinational Trial in Heart Failure; HF = heart failure; HOPE = Heart Outcomes Prevention Evaluation; LIPID = Long-term Intervention with Pravastatin in Ischaemic Disease; LIPS = Lescol Intervention Prevention Study; SSSS = Scandinavian Simvastatin Survival Study; WOSCOPS = The West of Scotland Coronary Prevention Study.

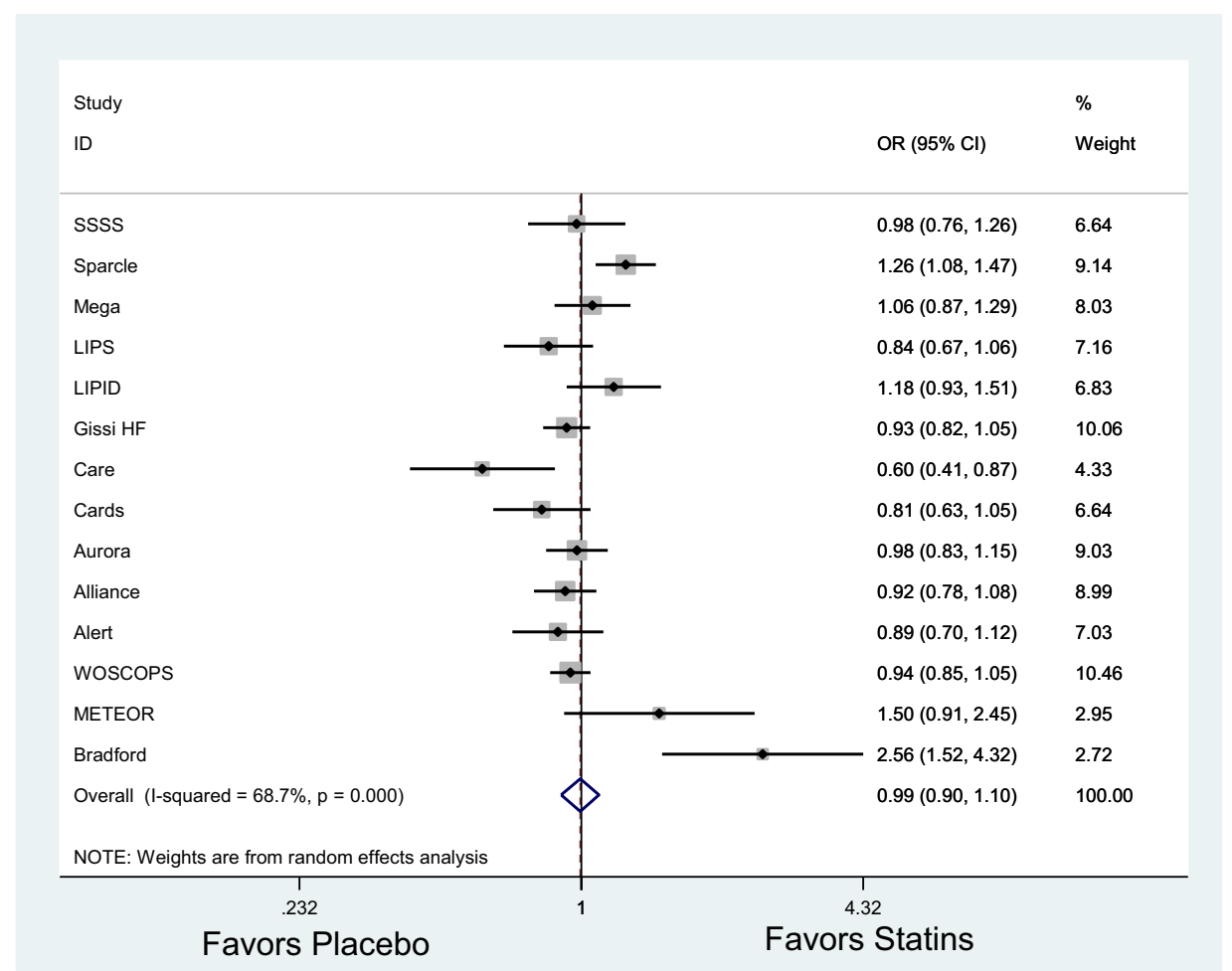

Figure 4. Rates of discontinuation after exclusion of the trials with the run-in phase. HF = heart failure; LIPS = Lescol Intervention Prevention Study; LIPID = Long-term Intervention with Pravastatin in Ischaemic Disease; METEOR = Measuring Effects on Intima-Media Thickness: an Evaluation of Rosuvastatin; SSSS = Scandinavian Simvastatin Survival Study; WOSCOPS = The West of Scotland Coronary Prevention Study. 


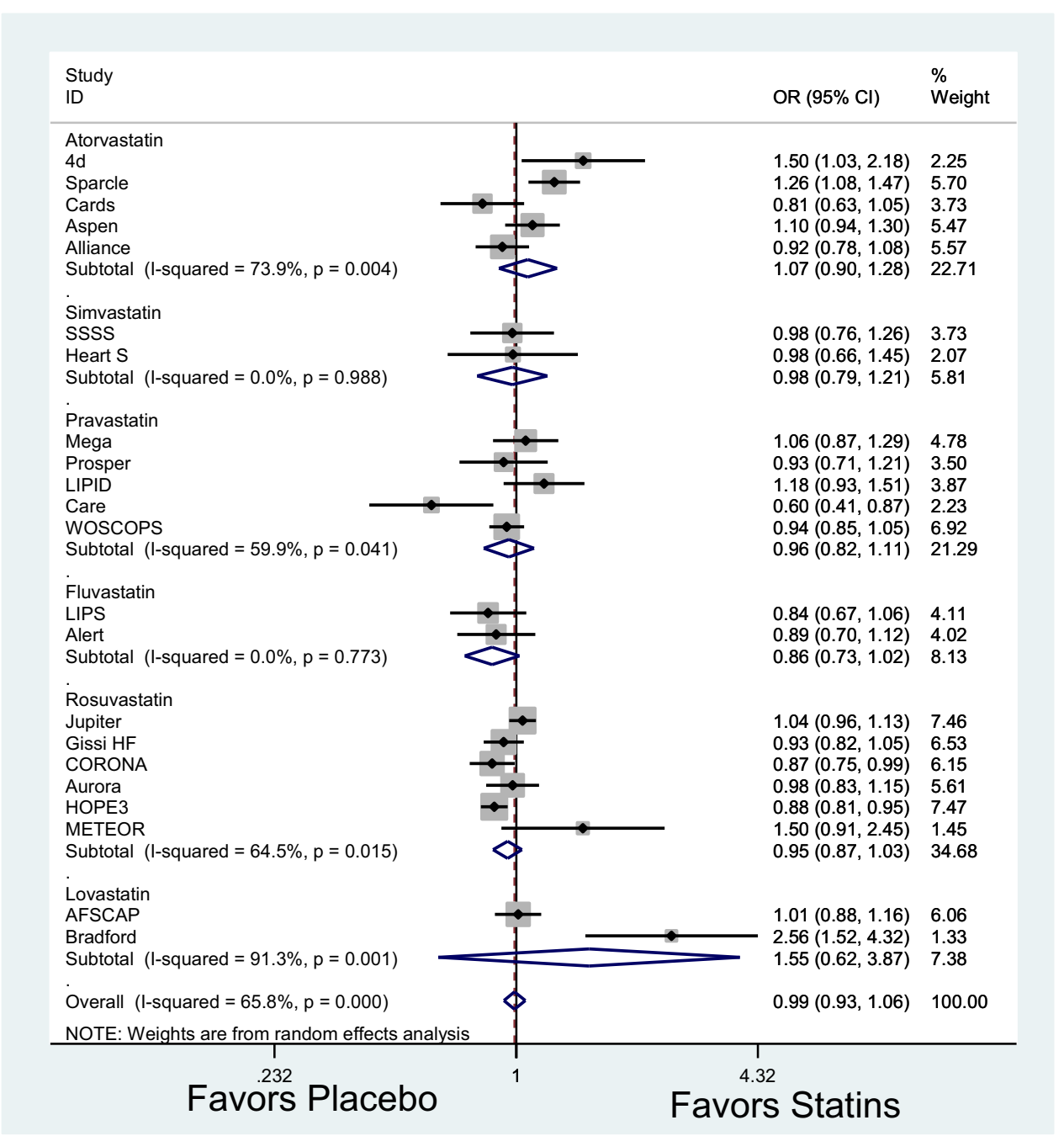

Figure 5. Rates of discontinuation according to the different statins. AFSCAP = The Air Force/Texas Coronary Atherosclerosis Prevention Study; CORONA $=$ Controlled Rosuvastatin Multinational Trial in Heart Failure; HF = heart failure; HOPE = Heart Outcomes Prevention Evaluation; LIPID = Long-term Intervention with Pravastatin in Ischaemic Disease; LIPS = Lescol Intervention Prevention Study; METEOR = Measuring Effects on Intima-Media Thickness: an Evaluation of Rosuvastatin; SSSS = Scandinavian Simvastatin Survival Study; WOSCOPS = The West of Scotland Coronary Prevention Study.

(as of November 23, 2016), thereby having the tendency to shape public opinion about the adverse effects of this important class of medications. Following the most recent update to the American College of Cardiology guidelines, any diabetic patient $>40$ years of age is very likely to require statin therapy. Given an estimated $10 \%$ incidence of statin intolerance, over 3 million patients are expected to develop intolerance. Recent studies suggest that patients intolerant to the statins can tolerate PCSK9 inhibitors. Compared with the statins, many of which are now available in generic form, PCSK9 inhibitors are an extremely expensive class of medications and should therefore be reserved for patients in whom statin use is prohibited due to considerable intolerance. ${ }^{26}$

We compared our findings with related systematic reviews. Cochrane database reviews related to the atorvastatin suggests that the use of atorvastatin compared with placebos is not associated with increased withdrawal-related events in a pooled analysis of 34 randomized trials. ${ }^{27}$ Ten of the 18 rosuvastatin placebo-controlled trials reported withdrawalrelated events, and the pooled analysis suggests that the rates of withdrawal are not significantly higher than placebos. ${ }^{28}$ Contrary to these findings, Golomb et al demonstrated that the use of statins is associated with a significantly increased risk of self-reported decreased energy and increased fatigue at 6 months compared with placebos in the UCSD trial. ${ }^{29}$ A 2013 Cochrane systematic review concluded that there is "no excess of adverse events among patients without evidence of CVD treated with statins." ${ }^{30}$ Interestingly, the rates of discontinuation and myopathy were not studied in this analysis and the conclusions were drawn on the basis of potentially catastrophic events such as cancer, hemorrhagic stroke, and incident diabetes.

It is important to note that the historical RCTs of statins represent strictly and carefully selected patients, and hence the results obtained may not be generalizable to the patients in the contemporary clinical practice. For example, in the Justification for the Use of Statins in Prevention: an Intervention Trial Evaluating Rosuvastatin trial, of the 89,890 patients screened, only 17,802 eventually participated in the trial. Moreover, several of these trials, including Justification for the Use 


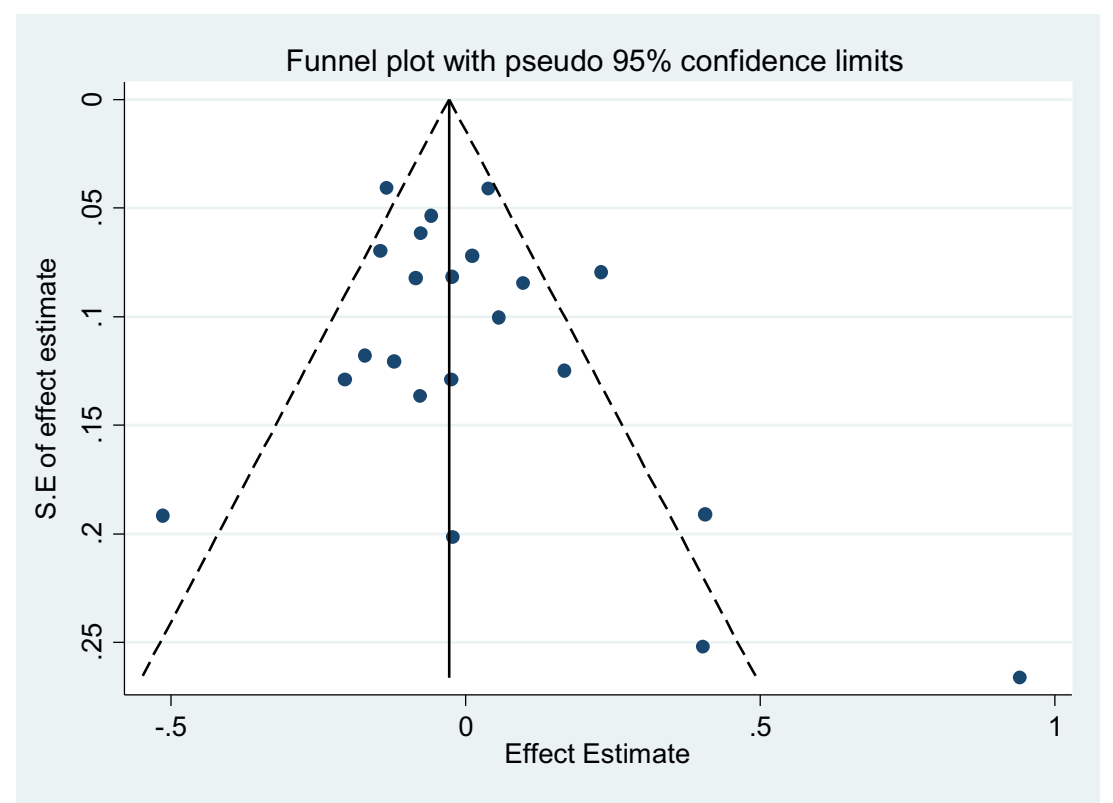

Figure 6. Funnel plot for publication bias. S.E $=$ standard error.

of Statins in Prevention: an Intervention Trial Evaluating Rosuvastatin, the Heart Protection Study, and the MEGA trial utilized an active drug run-in phase where patients were given active treatment and were only included in the randomized trial if they were found to be compliant with therapy. This inherently selects out those patients who are likely to be intolerant. Moreover, the doses of statins used in historical RCT were much lower than the doses of statins used in the contemporary clinical trials and current clinical practice. For instance, atorvastatin at $80 \mathrm{mg}$ or rosuvastatin at $40 \mathrm{mg}$ was used in contemporary RCT for secondary prevention, whereas the doses used in the historical RCT were much lower. This lower dosage may have also contributed to improved tolerance.

The Goal Achievement After Utilizing an Anti-PCSK9 Antibody in Statin Intolerant Subjects 3 trial addressed some of the gaps in the literature by randomizing the patients who were known to have muscle-related symptoms to statins or placebos. Based on the incidence of over $42 \%$ muscle-related symptoms, the authors concluded that the statin intolerance is a true phenomenon. However, almost $26 \%$ of patients who were challenged with placebos also experienced similar symptoms. This finding suggests that many of these symptoms may have little to do with the statin itself. It is important to note, however, that the dose of atorvastatin used in the Goal Achievement After Utilizing an Anti-PCSK9 Antibody in Statin Intolerant Subjects 3 trial was low (20 mg), making it possible that the trial underestimated the frequency of musclerelated symptoms.

Given the limitations of these RCTs, we hereby propose a pragmatic RCT of statins to address the issue of statin intolerance. Patients with very lenient inclusion criteria who are broadly representative of that general population should be randomized to high-dose statins versus placebo without a run-in phase. Because the efficacy of statins has been well established in terms of the reduction of Major Adverse Cardiovascular Events, the primary end point can be the rates of discontinuation. Therefore, this kind of a trial can be conducted with a lower sample size and a limited duration of follow-up.

These findings are limited by the heterogeneity of results, the variable duration of follow-up, and the lower doses of statins used in the trials compared with the contemporary clinical practice. We may also have an element of selection bias as RCTs have strict inclusion criteria, and hence, the generalizability of the results to the real-world patients may be limited. Physicians should provide reassurance to patients who present with potential statin intolerance given the consistent and proven track record of statins for CVD prevention. Among patients with persistent intolerance, efforts should be made to reduce drug dosing or to change to a different type of statin before discontinuing the lipid-lowering therapy or changing to a less proven class of drugs.

\section{Disclosures}

The authors have no conflicts of interest to disclose.

1. Nissen SE, Stroes E, Dent-Acosta RE, Rosenson RS, Lehman SJ, Sattar N, Preiss D, Bruckert E, Ceška R, Lepor N, Ballantyne CM, GouniBerthold I, Elliott M, Brennan DM, Wasserman SM, Somaratne R, Scott $\mathrm{R}$, Stein EA. Efficacy and tolerability of evolocumab vs ezetimibe in patients with muscle-related statin intolerance: the GAUSS-3 randomized clinical trial. JAMA 2016;315:1580-1590.

2. Arnold SV, Spertus JA, Tang F, Krumholz HM, Borden WB, Farmer SA, Ting HH, Chan PS. Statin use in outpatients with obstructive coronary artery disease. Circulation 2011;124:2405-2410.

3. Stone NJ, Robinson J, Lichtenstein AH, Bairey Merz CN, Blum CB, Eckel RH, Goldberg AC, Gordon D, Levy D, Lloyd-Jones DM, McBride P, Schwartz JS, Shero ST, Smith SC Jr, Watson K, Wilson PW, Eddleman KM, Jarrett NM, LaBresh K, Nevo L, Wnek J, Anderson JL, Halperin JL, Albert NM, Bozkurt B, Brindis RG, Curtis LH, DeMets D, Hochman JS, Kovacs RJ, Ohman EM, Pressler SJ, Sellke FW, Shen WK, Smith SC Jr, Tomaselli GF. 2013 ACC/AHA guideline on the treatment of blood cholesterol to reduce atherosclerotic cardiovascular risk in adults: a report 
of the American College of Cardiology/American Heart Association Task Force on Practice Guidelines. Circulation 2014;129:S1-S45.

4. Wanner C, Krane V, März W, Olschewski M, Mann JF, Ruf G, Ritz E. Atorvastatin in patients with type 2 diabetes mellitus undergoing hemodialysis. N Engl J Med 2005;353:238-248.

5. Downs JR, Clearfield M, Weis S, Whitney E, Shapiro DR, Beere PA, Langendorfer A, Stein EA, Kruyer W, Gotto AM Jr, AFCAPS/ TexCAPS Research Group. Primary prevention of acute coronary events with lovastatin in men and women with average cholesterol levels: results of AFCAPS/TexCAPS. JAMA 1998;279:1615-1622.

6. Holdaas H, Fellström B, Jardine AG, Holme I, Nyberg G, Fauchald P, Grönhagen-Riska C, Madsen S, Neumayer HH, Cole E, Maes B. Effect of fluvastatin on cardiac outcomes in renal transplant recipients: a multicentre, randomised, placebo-controlled trial. Lancet 2003;361:20242031.

7. Koren MJ, Hunninghake DB. Clinical outcomes in managed-care patients with coronary heart disease treated aggressively in lipidlowering disease management clinics: the alliance study. J Am Coll Cardiol 2004;44:1772-1779.

8. Knopp RH, d'Emden M, Smilde JG, Pocock SJ. Efficacy and safety of atorvastatin in the prevention of cardiovascular end points in subjects with type 2 diabetes the Atorvastatin Study for Prevention of Coronary Heart Disease Endpoints in Non-Insulin-Dependent Diabetes Mellitus. Diabetes Care 2006;29:1478-1485.

9. Fellström BC, Jardine AG, Schmieder RE, Holdaas H, Bannister K, Beutler J, Chae DW, Chevaile A, Cobbe SM, Grönhagen-Riska C, De Lima JJ. Rosuvastatin and cardiovascular events in patients undergoing hemodialysis. N Engl J Med 2009;360:1395-1407.

10. Colhoun HM, Betteridge DJ, Durrington PN, Hitman GA, Neil HA, Livingstone SJ, Thomason MJ, Mackness MI, Charlton-Menys V, Fuller $\mathrm{JH}$. Primary prevention of cardiovascular disease with atorvastatin in type 2 diabetes in the Collaborative Atorvastatin Diabetes Study: multicentre randomised placebo-controlled trial. Lancet 2004;364:685696.

11. Sacks FM, Pfeffer MA, Moye LA, Rouleau JL, Rutherford JD, Cole TG, Brown L, Warnica JW, Arnold JM, Wun CC, Davis BR. The effect of pravastatin on coronary events after myocardial infarction in patients with average cholesterol levels. N Engl J Med 1996;335:1001-1009.

12. Kjekshus J, Apetrei E, Barrios V, Böhm M, Cleland JG, Cornel JH, Dunselman P, Fonseca C, Goudev A, Grande P, Gullestad L. Rosuvastatin in older patients with systolic heart failure. N Engl J Med 2007;357:22482261.

13. Tavazzi L, Maggioni AP, Marchioli R, Barlera S, Franzosi MG, Latini R, Lucci D, Nicolosi GL, Porcu M, Tognoni G. Effect of rosuvastatin in patients with chronic heart failure: a randomised, double-blind, placebocontrolled trial. Lancet 2008;372:1231-1239.

14. Heart Protection Study Collaborative Group. MRC/BHF Heart Protection Study of cholesterol lowering with simvastatin in 20536 highrisk individuals: a randomised placebo controlled trial. Lancet 2002;360:722.

15. Ridker PM, Danielson E, Fonseca FA, Genest J, Gotto AM Jr, Kastelein JJ, Koenig W, Libby P, Lorenzatti AJ, MacFadyen JG, Nordestgaard BG. Rosuvastatin to prevent vascular events in men and women with elevated C-reactive protein. N Engl J Med 2008;359:2195.

16. Tonkin A, Alyward P, Colquhoun D, Glasziou P, Harris P, Hunt D, Keech A, MacMahon S, Magnus P, Newel D, Nestel P. Prevention of cardio- vascular events and death with pravastatin in patients with coronary heart disease and a broad range of initial cholesterol levels. N Engl J Med 1998;339:1349-1357.

17. Serruys PW, de Feyter P, Macaya C, Kokott N, Puel J, Vrolix M, Branzi A, Bertolami MC, Jackson G, Strauss B, Meier B. Fluvastatin for prevention of cardiac events following successful first percutaneous coronary intervention: a randomized controlled trial. JAMA 2002;287:3215-3222.

18. Nakamura H, Arakawa K, Itakura H, Kitabatake A, Goto Y, Toyota T, Nakaya N, Nishimoto S, Muranaka M, Yamamoto A, Mizuno K. Primary prevention of cardiovascular disease with pravastatin in Japan: a prospective randomised controlled trial. Lancet 2006;368:1155-1163.

19. Shepherd J, Blauw GJ, Murphy MB, Bollen EL, Buckley BM, Cobbe SM, Ford I, Gaw A, Hyland M, Jukema JW, Kamper AM. Pravastatin in elderly individuals at risk of vascular disease (PROSPER): a randomised controlled trial. Lancet 2002;360:1623-1630.

20. Stroke Prevention by Aggressive Reduction in Cholesterol Levels (SPARCL) Investigators. High-dose atorvastatin after stroke or transient ischemic attack. $N$ Engl J Med 2006;2006:549-559.

21. Scandinavian Simvastatin Survival Study Group. Randomised trial of cholesterol lowering in 4444 patients with coronary heart disease: the Scandinavian Simvastatin Survival Study (4S). Lancet 1994;344:13831389.

22. Shepherd J, Cobbe SM, Ford I, Isles CG, Lorimer AR, Macfarlane PW, McKillop JH, Packard CJ. Prevention of coronary heart disease with pravastatin in men with hypercholesterolemia. N Engl J Med 1995:333:1301-1308.

23. Yusuf S, Bosch J, Dagenais G, Zhu J, Xavier D, Liu L, Pais P, LópezJaramillo P, Leiter LA, Dans A, Avezum A, Piegas LS, Parkhomenko A, Keltai K, Keltai M, Sliwa K, Peters RJ, Held C, Chazova I, Yusoff K, Lewis BS, Jansky P, Khunti K, Toff WD, Reid CM, Varigos J, Sanchez-Vallejo G, McKelvie R, Pogue J, Jung H, Gao P, Diaz R, Lonn E. Cholesterol lowering in intermediate-risk persons without cardiovascular disease. N Engl J Med 2016;374:2021-2031.

24. Crouse JR 3rd, Raichlen JS, Riley WA, Evans GW, Palmer MK, O'Leary DH, Grobbee DE, Bots ML. Effect of rosuvastatin on progression of carotid intima-media thickness in low-risk individuals with subclinical atherosclerosis: the METEOR Trial. JAMA 2007;297:1344-1353.

25. Bradford RH, Downton M, Chremos AN, Langendörfer A, Stinnett S, Nash DT, Mantell G, Shear CL. Efficacy and tolerability of lovastatin in 3390 women with moderate hypercholesterolemia. Ann Intern Med 1993;118:850-855.

26. Kazi DS, Moran AE, Coxson PG, Penko J, Ollendorf DA, Pearson SD, Tice JA, Guzman D, Bibbins-Domingo K. Cost-effectiveness of PCSK9 inhibitor therapy in patients with homozygous familial hypercholesterolemia or atherosclerotic cardiovascular disease. JAMA 2016;316:743753.

27. Adams SP, Tsang M, Wright JM. Lipid-lowering efficacy of atorvastatin. Cochrane Database Syst Rev 2015;(3):CD008226.

28. Adams SP, Sekhon SS, Wright JM. Lipid-lowering efficacy of rosuvastatin. Cochrane Database Syst Rev 2014;(11):CD010254.

29. Golomb BA, Evans MA, Dimsdale JE, White HL. Effects of statins on energy and fatigue with exertion: results from a randomized controlled trial. Arch Intern Med 2012;172:1180-1182.

30. Taylor F, Huffman MD, Macedo AF, Moore THM, Burke M, Davey SG, Ward K, Ebrahim S. Statins for the primary prevention of cardiovascular disease. Cochrane Database Syst Rev 2013;(1):CD004816. 